\title{
Effect of axial loads on implant-supported partial fixed prostheses by strain gauge analysis
}

\author{
Luis Gustavo Oliveira de VASCONCELLOS ${ }^{1}$, Renato Sussumu NISHIOKA², Luana Marotta Reis de VASCONCELLOS ${ }^{3}$, \\ Lea Nogueira Braulino de Melo NISHIOKA ${ }^{4}$
}

1- DDS, MS, Department of Dental Materials and Prosthodontics, São José dos Campos Dental School, São Paulo State University, São José dos Campos,
SP, Brazil.
2- DDS, MS, PhD, Department of Dental Materials and Prosthodontics, São José dos Campos Dental School, São Paulo State University, São José dos
Campos, SP, Brazil.
3- DDS, MS, PhD, Department of Bioscience and Buccal Diagnosis, São José dos Campos Dental School, São Paulo State University, São José dos Campos,
SP, Brazil.
4- Mech Eng, MS, Department of Mechanical Engineering, Institute of Science Technology - CETEC, São José dos Campos, SP, Brazil.

Corresponding address: Luis Gustavo Oliveira de Vasconcellos - Alameda Harvey C. Weeks, 14 - sala 09 - Vista Verde - São José dos Campos - SP - Brasil - 12223-830 - Phone: +55-12-3912 2342 - Fax: +55-12-39479010 - e-mail: Igovasconcellos11@terra.com.br or luis.vasconcellos@alunos.fosjc.unesp.br

Received: October 15, 2009 - Modification: May 02, 2010 - Accepted: May 30, 2010

\section{ABSTRACT}

\begin{abstract}
bjectives: The present study used strain gauge analysis to perform an in vitro evaluation of the effect of axial loading on 3 elements of implant-supported partial fixed prostheses, varying the type of prosthetic cylinder and the loading points. Material and methods: Three internal hexagon implants were linearly embedded in a polyurethane block. Microunit abutments were connected to the implants applying a torque of $20 \mathrm{Ncm}$, and prefabricated $\mathrm{Co}-\mathrm{Cr}$ cylinders and plastic prosthetic cylinders were screwed onto the abutments, which received standard patterns cast in $\mathrm{Co}-\mathrm{Cr}$ alloy $(n=5)$. Four strain gauges (SG) were bonded onto the surface of the block tangentially to the implants, SG 01 mesially to implant 1, SG 02 and SG 03 mesially and distally to implant 2, respectively, and SG 04 distally to implant 3. Each metallic structure was screwed onto the abutments with a $10 \mathrm{Ncm}$ torque and an axial load of $30 \mathrm{~kg}$ was applied at five predetermined points $(A, B$, $C, D, E)$. The data obtained from the strain gauge analyses were analyzed statistically by RM ANOVA and Tukey's test, with a level of significance of $p<0.05$. Results: There was a significant difference for the loading point $(p=0.0001)$, with point $B$ generating the smallest microdeformation $(239.49 \mu \varepsilon)$ and point $D$ the highest $(442.77 \mu \varepsilon)$. No significant difference was found for the cylinder type $(p=0.748)$. Conclusions: It was concluded that the type of cylinder did not affect in the magnitude of microdeformation, but the axial loading location influenced this magnitude.
\end{abstract}

Key words: Biomechanics. Dental implants. Dental prosthesis. Implant-supported dental prosthesis.

\section{INTRODUCTION}

Occlusal overload has been given as the primary factor for peri-implant bone loss, as well as loss of implants and of implant-supported prosthese ${ }^{10,12}$. The transfer of occlusal load is related with several factors such as: a) geometry - position and number of implants $4,18,24,26,27,29$, linear or off-set arrangement of the implants ${ }^{22,24}$, cantilever extension ${ }^{18,24}$, a displaced occlusal plane ${ }^{24}$, size of the occlusal table ${ }^{18,23,24}$, excessive height of the abutment/ crown $\operatorname{set}^{24}$; b) occlusion - parafunctional habits ${ }^{18}$, bite force ${ }^{18,23}$, occlusal contacts ${ }^{6,27}$; c) load-bearing capacity of bone - bone density and quality ${ }^{28}$, primary mechanical stability ${ }^{24}$, healing time ${ }^{24}$; and d) technological - precision of the implant/abutment and abutment/prosthesis interfaces ${ }^{8,20,24}$, amount of preload $^{24}$, and type of prosthetic retention ${ }^{8,9,24}$.

Occlusal loads are first introduced to the prosthesis, and are delivered to the bone/ implant interface ${ }^{25}$; hence, the development and maintenance of the bone/implant interface is particularly dependent on the control of biomechanical loads. Bones carrying mechanical 
loads adapt their strength to the load applied on them by bone modeling/remodeling. The response to an increased mechanical stress below a certain threshold will be a strengthening of the bone by increasing the bone density or apposition of bone. On the other hand, fatigue micro-damage resulting in bone resorption may be the result of mechanical stress beyond this threshold $7,12,30$.

Compared to implant-supported total fixed prostheses, implant-supported partial fixed prostheses are more susceptible to the moment generated by occlusal loads, since they lack the benefit of cross-arch stabilization ${ }^{24}$. Moreover, the posterior region of the oral cavity presents higher occlusal loading and lower bone quality than the anterior region; additionally, bone height is limited by the maxillary sinus or the mandibular nerve. In a retrospective clinical analysis of the relation between the fracture of implants and occlusal overload, Rangert, et al. ${ }^{24}$ (1997) found that $90 \%$ of implant fractures occurred in the posterior segment, supported by one or more implants, in association with cantilever, bruxism or high occlusal loads.

Recent studies have investigated the stresses caused by implant-supported prosthesis fabrication methods, by varying the type of cylinder $r^{8,9,15,16}$. However, these studies observed stresses only during the fixation of implant-supported fixed partial prostheses.

Strain gauge analysis has been used to evaluate stresses in implant-supported prostheses, both in vitro ${ }^{3,15,22}$ and in vivo ${ }^{9,16}$, under static ${ }^{1,4,26 \text {, }}$ and/or dynamic loads 5 . Depending on the site to be evaluated, strain gauges can be bonded close to implants ${ }^{4,9,22}$, on the implants ${ }^{1,19}$, on the abutments ${ }^{19,26}$, and on the metal structures of the prosthesis ${ }^{3,9,17}$.

The objective of the present study was to compare the magnitude of peri-implant microdeformation of three-element fixed partial prostheses obtained from prefabricated and plastic cylinders subjected to axial loads.

\section{MATERIAL AND METHODS}

To simulate clinical conditions in a reallife arrangement, three internal hexagon type implants from mesial to distal: labeled 1, 2, and 3 (Conect AR; 3.75-mm diameter, 13- $\mathrm{mm}$ depth; Conexão Sistemas de Prótese, Arujá, SP, Brazil) were arranged in the middle of a measurement model consisting of a $70 \times 40 \times 30 \mathrm{~mm}^{3}$ rectangular polyurethane block (Polyurethane F16, Axson, Cergy, France) with known mechanical properties (Young's modulus of $3.6 \mathrm{GPa}$ ). One matrix that could generate a constant implant placement was custom-built. The implants were embedded in a straight line in the polyurethane block. The distance between the centers of the implants was set at 7 $\mathrm{mm}$, leaving sufficient space for the strain gauge (SG) (Figure 1).

Microunit abutments (Micro unit; Conexão Sistemas de Prótese) were screwed onto the implants with a $20 \mathrm{Ncm}$ torque using the implant manufacturer's manual torque driver (Torque driver; Conexão Sistemas de Prótese).

The patterns were fabricated using a pattern resin (GC Pattern Resin; GC Europe N.V., Leuven, Belgium) and wax (Kronen wachs; Bego Bremer Goldschalgerei, Bremen, Germany). The 10 superstructures were made on the polyurethane blocks. The components were connected to the Microunit abutment to eliminate the inevitable dimensional changes originating from impression procedures $^{8}$. The superstructures were fabricated using plastic cylinders (Plastic coping; Conexão Sistemas de Prótese) and pre-machined cobaltchromium cylinders (Machined coping; Conexão Sistemas de Prótese). The superstructures were sprued, invested, and cast using a cobalt-chromium alloy (Wirobond SG, Bego Bremer Goldschalgerei, Bremen, Germany). To avoid bias resulting from manufacturing conditions, random sets comprising frameworks of different types were put together and cast. The superstructures were fabricated using the 1-piece method. The castings were cleaned, finished, and polished, and care was taken not to damage the internal surface of the copings, whose interiors were inspected under a binocular microscope to check for casting imperfections. The abutments received three-unit superstructures, and each group consisted of five superstructures. The fit and passivity of the superstructures were checked without torque tightening. The superstructures showed satisfactory adaptation which was confirmed by direct vision in conjunction with tactile sensation through an explorer ${ }^{13}$. Superstructures showing signs of instability were excluded.

Four strain gauges (SGs) (KFG-02-120-c1$11 \mathrm{~N} 30 \mathrm{C} 2$, Kyowa Electronic Instruments Co., Ltd, Tokyo, Japan) were bonded onto the surface of each polyurethane block using a thin film of methyl-2-cyanoacrylate adhesive (M-Bond 200; Vishay Measurements Group, Raleigh, NC, USA). SG 01 was placed mesially adjacent to implant 1 , SG 02 and SG 03 were placed mesially and distally

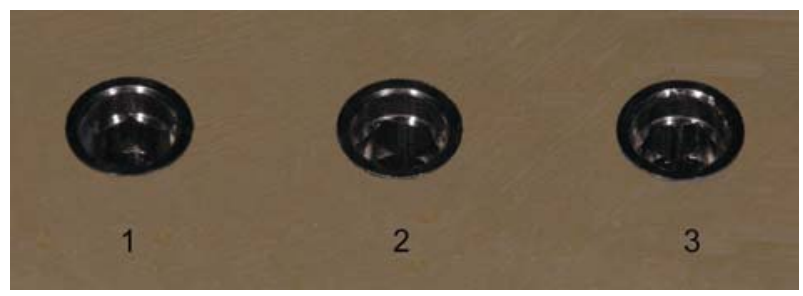

Figure 1- Positioning of the internal hexagon implants, showing the equidistance and linear configuration 


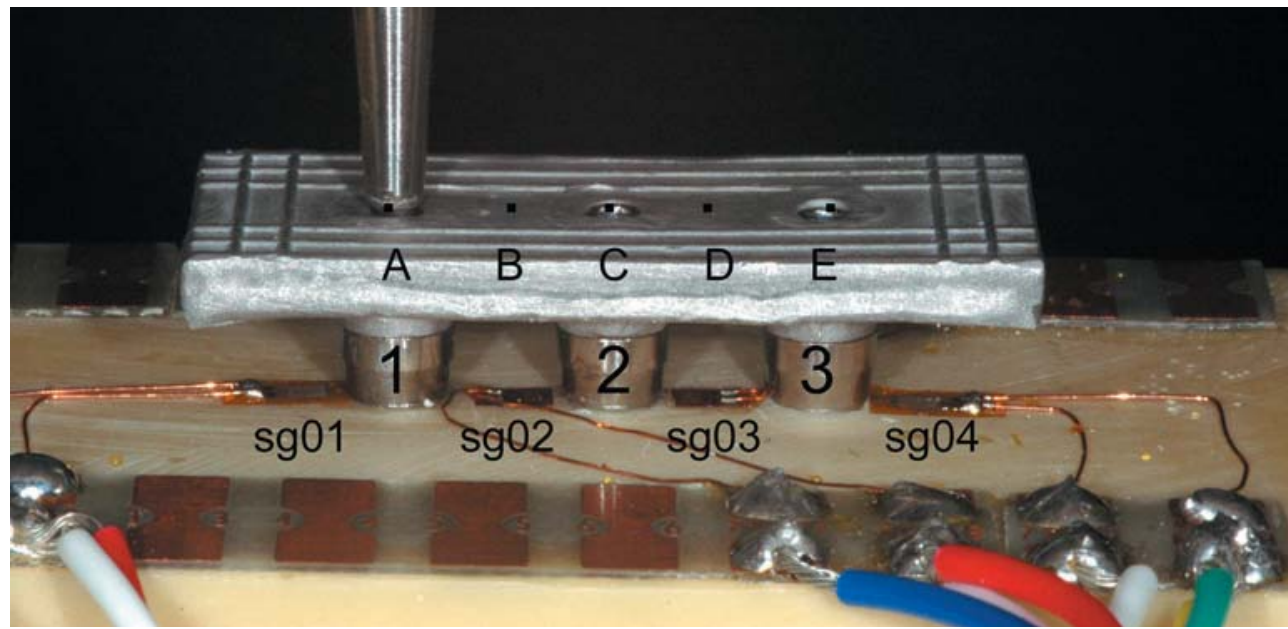

Figure 2- Detail of static vertical loading on loading point $A$

adjacent to implant 2, respectively, and SG 04 was placed distally adjacent to implant 3 . Each gauge was wired separately, and the 4 strain gauges were arranged in series to form a full Wheatstone bridge. The leads from the strain gauges were connected to a multichannel bridge amplifier to form one leg of the bridge. A computer (Intel 775P Pentium 4 Q6600) was interfaced with the bridge amplifier to record the output signal of polyurethane surface. Data-acquisition system software (System 5000 Model 5100B; Vishay Measurements Group, Raleigh, NC, USA) was used to record the data.

The superstructure's occlusal screws were tightened onto the Microunit abutments with a hand-operated screwdriver until the screws started to engage, based on tactile sensation, while applying a torque of $10 \mathrm{Ncm}$ using the manufacture's manual torque-controlling device.

Five loading points were selected to apply a static vertical load on the metallic superstructures. Point A was located on the hole of the retention screw of implant 1, point B was located centrally between the holes of the retention screws of implants 1 and 2 , point $\mathrm{C}$ was located on the hole of the retention screw of implant 2, point D was located centrally between the hole of the retention screws of implants 2 and 3, and point $E$ was located on the hole of the retention screw of implant 3 .

All of the strain gauges were zeroed and calibrated prior to each loading and a vertical load of $30 \mathrm{~kg}^{21}$ was applied for $10 \mathrm{~s}$, using a universal load-testing machine (DL-1000; EMIC, São José dos Pinhais, PR, Brazil). The magnitude of microdeformation on each strain gauge was recorded in units of microdeformation $(\mu \varepsilon)$. This procedure was repeated two more times, making a total of 3 loads per loading point (Figure 2).

In order to compare the magnitude of microdeformation resulting from the type of cylinder and the loading point, the positive and negative strains recorded in the strain gauge analysis were transformed into absolute values $8,16,17,26$, which were used to calculate the mean values of microdeformation of each strain gauge.

This experiment followed a factorial scheme of the $2 \times 5$ type. The experimental variables under study were cylinder (plastic and pre-fabricated) and loading point ( $A, B, C, D, E)$. The variable response was the micro-deformation value obtained in the strain-gauge analysis. The experimental unit was the prosthetic superstructure. The test specimens were randomly assigned to the loading point conditions.

Fifty (50) data obtained were submitted to statistical analysis using the following statistical softwares: GraphPad Prism version 4.00, 2003 (GraphPad Software, Inc., La Jolla, CA, USA), Minitab version 14.12, 2004 (Minitab Corporation, State College, PA, USA) and Statix version 8.0, 2003 (Analytical Software Inc., version 8.0, 2003; Tallahassee, FL, USA). The descriptive statistics consisted of the calculation of the means and standard deviations. The inferential statistics consisted of analysis of variance of repeated measurements of two factors (cylinder and loading point), in which the variable loading point was considered as a repeated factor. The study of the interaction effect was conducted by graph means. Multiple comparisons among the means for the five experimental conditions were made by the Tukey's multiple-comparison test. Significance level was set at $5 \%$.

\section{RESULTS}

Table 1 lists the descriptive statistical data, analyzing the mean values of microdeformation obtained with each strain gauge (SG) and mean of 4 strain gauges for the plastic prosthetic cylinders and the prefabricated $\mathrm{Co}-\mathrm{Cr}$ cylinders at each loading point.

Table 1 shows the microdeformation values $(\mu \varepsilon)$ 
Table 1- Mean values and standard deviations of microdeformation $(\mu \varepsilon)$ measured by each strain gauge and mean of 4 strain gauges at each loading point for the plastic and prefabricated cylinders

\begin{tabular}{ccccccc}
\hline Cylinder & Loading point & SG 01 & SG 02 & SG 03 & SG 04 & Mean of 4SG \\
\hline Plastic $(n=5)$ & A & $568.8 \pm 133.0$ & $306.2 \pm 138.3$ & $55.4 \pm 39.2$ & $256.8 \pm 130.6$ & $296.6 \pm 77.68$ \\
& B & $605.3 \pm 64.4$ & $156.4 \pm 123.4$ & $34.4 \pm 39.6$ & $167.1 \pm 93.3$ & $240.8 \pm 42.41$ \\
\hline & C & $463.9 \pm 40.4$ & $175.3 \pm 124.9$ & $67.1 \pm 44.4$ & $535.0 \pm 184.8$ & $310.3 \pm 19.92$ \\
\hline Pre-fabricated $(n=5)$ & D & $349.8 \pm 45.4$ & $369.4 \pm 152.5$ & $190.2 \pm 65.8$ & $937.0 \pm 112.8$ & $461.6 \pm 59.46$ \\
& E & $156.6 \pm 69.4$ & $444.6 \pm 128.4$ & $115.1 \pm 91.9$ & $1044.6 \pm 127.7$ & $440.2 \pm 43.18$ \\
& A & $617.4 \pm 100.7$ & $205.0 \pm 148.8$ & $31.83 \pm 20.49$ & $319.2 \pm 32.0$ & $293.4 \pm 64.0$ \\
\hline & B & $634.1 \pm 104.3$ & $118.9 \pm 57.0$ & $39.88 \pm 16.45$ & $150.9 \pm 140.3$ & $238.2 \pm 51.77$ \\
& C & $563.5 \pm 46.5$ & $145.8 \pm 121.9$ & $83.3 \pm 67.4$ & $451.1 \pm 170.8$ & $310.9 \pm 56.08$ \\
\hline & D & $389.5 \pm 56.3$ & $267.8 \pm 108.9$ & $154.3 \pm 46.1$ & $884.1 \pm 140.1$ & $423.9 \pm 55.44$ \\
\hline
\end{tabular}

obtained, analyzing the mean values of microstrain obtained by the four strain gauges (SG) positioned around the implant, for five loading point $(A, B, C$, $D, E)$, as well as the type of cylinders (plastic and prefabricated).

The statistical RM ANOVA indicated that the loading point effect was statistically significant $(p=0.0001)$, while the interaction effect was not statistically significant, demonstrating that the cylinder effect was the same for each loading point.

Tukey's multiple-comparison test was then applied to compare the mean values of the 5 levels of the loading point factor (Table 2).

Table 2- Mean values of the 5 levels of the loading point factor

\begin{tabular}{cc}
\hline Loading point & Mean $(\mu \varepsilon)$ \\
\hline D & $442.77^{\mathrm{A}}$ \\
E & $439.28^{\mathrm{A}}$ \\
C & $310.63^{\mathrm{B}}$ \\
A & $295.00^{\mathrm{B}}$ \\
B & $239.49^{\mathrm{C}}$ \\
\hline
\end{tabular}

*Same superscript letters mean no significant difference at 5\% (Tukey's test).

\section{DISCUSSION}

When an occlusal load is applied upon an implant, the load is partially transferred to the bone, with the highest stresses occurring in the implant's most cervical region. This phenomenon is due to one of the principles of engineering, i.e., when two materials are in contact with each other and one of them is loaded, the stresses will be higher at the materials' initial point of contact ${ }^{11}$. Therefore, the cervical region of the implant is the site where the greatest microdeformations occur $^{17,18}$, independently of the type of bone and the design of the implant ${ }^{28}$, the configuration of the prosthesis and the load 27 . In the present study, strain gauges were strategically bonded on the polyurethane block, tangentially to the implant platform, to observe the region with the highest concentration of stresses during the application of loads, to correlate it with clinical practice ${ }^{17}$. This positioning of the strain gauges has also been used in previous studies $4,8,9,15,17,22$. The flat surface of the polyurethane block made the positioning and bonding of the stain gauges simpler and more precise than in other studies, which opted for bonding on the implants ${ }^{1,19}$, on the abutments ${ }^{19,26}$, and on the metal structures of the prosthesis ${ }^{9,17}$.

According to Frost ${ }^{7}$ (1994) and Wiskott and Belser $^{30}$ (1999), bone homeostasis occurs when the level of microdeformation remains within the range of 100 to $2000 \mu \varepsilon$ and 50 to $1500 u \varepsilon$, respectively. In Table 1, most of the microdeformation values obtained for both the plastic and the prefabricated cylinders remained within the level of bone homeostasis, or normal load. However, this ideal clinical situation of occlusal contacts is difficult to achieve with an implant-supported partial fixed prosthesis because the hole of the retention screw makes it impossible to position the occlusal contacts in the center of the implant. Nevertheless, based on the results of the current work, it can be inferred that, when a 3-element partial fixed prosthesis supported by 3 implants is loaded axially, with occlusal contacts positioned between the implants and as close as possible to the latter, bone resorption around the implants and occlusal overload can be minimized. If the load were applied around the center of the implants, the torque or moment would be greater, since the torque is directly proportional to the distance between the loading point and the center of the implant ${ }^{24}$.

In the present study, it was found that when 
loads were applied on loading points A, B, D and E, which were positioned on and close to the implants at the extremities, the largest microdeformations occurred in the closest strain gauges, indicating that the amount of load transmitted to the implant and the stresses generated in the bone depend on the location where the load is applied on the prosthesis. In contrast, when loads were applied on loading point $\mathrm{C}$, which was positioned on the central implant, the greatest microdeformations occurred in the most distant strain gauges, indicating that the implants at the extremities were more loaded (Table 1). These results suggest that the stresses generated by occlusal contacts located close to the central implant of the screwed fixed partial prosthesis supported on three implants are distributed to the implants at the extremities, while the stresses generated by occlusal contacts positioned close to the implants at the extremities concentrate in those implants.

Misfit at the abutment/prosthesis interface may lead to significant instability of the implantsupported prosthesis, which increases linearly as a function of the degree of misfit $^{20}$. The precision of the interfaces may also negatively affect the load-bearing ability of the implant-supported prosthesis ${ }^{24}$, affecting the magnitude of the forces in the peri-implantar region ${ }^{25}$. The inaccurate fit of the superstructures can attribute to the impression technique, the control of laboratory analogues, or soldering method. The procedure that attempts to compensate for shrinkage or deformation, the one-piece casting method, waxing was performed directly on the abutment in polyurethane block ${ }^{8}$. Studies to evaluate the fit of the abutment/ prosthesis interface have demonstrated that the precision of unitary metallic structures obtained with prefabricated cylinders is better than that obtained with plastic cylinders 2,14 . However, it should be noted that the care involved in handling multiple prostheses is very different from that involved in handling single ones, and the complexity of the laboratory procedures increases proportionally to the number of fixations involved.

In this present study, the cylinder effect and the cylinder/loading point interaction showed no statistically significant difference. This finding suggests that the type of cylinder, plastic or prefabricated, does not affect the magnitude of microdeformation when an implant-supported fixed prosthesis is axially loaded, and that the behavior of both cylinders followed the same pattern at all of the loading points, showing no significant difference. Previous strain gauge studies have reported similar results ${ }^{8,9,15}$, with fixed partial prostheses screwed onto implants, made from plastic or prefabricated cylinders, producing the same magnitude of microdeformation during tightening of the retention screws, without significant difference between plastic and prefabricated cylinders before ${ }^{8,9}$ and after ${ }^{15}$ the application of a dental ceramic.

With regard to the loading point effect, a significant difference was found $(p=0.0001)$, suggesting that symmetrical loading points, $A$ versus $E$ and $B$ versus $D$, did not produce similar magnitudes of microdeformation. The superstructures showed satisfactory adaptation which was confirmed by direct vision in conjunction with tactile sensation through an explorer. Therefore, the method used is not able to detect slight distortions of the prosthesis on the implant ${ }^{13}$, probably caused by casting procedures of the implant-supported fixed partial prosthesis. This finding suggests that the fit of the cast metal rods was not homogeneous, i.e., the fit attained by the cast metal rods in implant 3 may have differed from that found in implant 1 , which in turn may also have differed from the fit obtained in implant 2. Thus, the nonhomogeneous fit may have influenced the distribution of stresses, producing different magnitudes of microdeformation, even when the load was applied on equidistant and symmetrical points.

Limitations of the present model must be taken into account when interpreting the results of this investigation. This is an in vitro study based on a homogenous model with known mechanical properties instead of bone, which allowed not only proper strain measurements, but also $100 \%$ implant-model material contact. In vivo, additional variables like bone density, implant stability, and bone-to-implant contact would have to be considered. The interimplant relationships represented a straight-line configuration of the implants, which seems to be also a simplified situation compared to a curved distribution with a longer segment splinted. The flat occlusal surface of the superstructures did not represent the "real clinical situation", variables such as cusp inclination, occlusal table and location, direction and magnitude of applied occlusal forces on the superstructures could change the results of this study.

\section{CONCLUSION}

Based on the obtained results, type of cylinder, plastic or prefabricated, did not affect in the magnitude of microdeformation under axial loading and the location of the applied axial loads affected the magnitude of microdeformation. 


\section{REFERENCES}

1- Akça K, Çehreli MC, Iplikçioglu H. A comparison of threedimensional finite element stress analysis with in vitro strain gauge measurements on dental implants. Int J Prosthodont. 2002;15:115-21.

2- Carr AB, Brunski JB, Hurley E. Effects of fabrication, finishing, and polishing procedures on preload in prostheses using conventional "gold" and plastic cylinders. Int J Oral Maxillofac Implants. 1996;11:589-98.

3- Castilho AA, Kojima AN, Pereira SM, Vasconcellos DK, Itinoche $\mathrm{MK}$, Faria $\mathrm{R}$, et al. In vitro evaluation of the precision of working casts for implant-supported restoration with multiple abutments. J Appl Oral Sci. 2007;15:241-6.

4- Çehreli MC, Akça K. Narrow-diameter implants as terminal support for occlusal three-unit FPDs: a biomechanical analysis. Int J Periodontics Restor Dent. 2004;24:513-9.

5- Çehreli MC, Akkocaoglu M, Comert A, Tekdemir I, Akca K. Human ex vivo bone tissue strains around natural teeth vs. immediate oral implants. Clin Oral Implants Res. 2005;16:540-8. 6- Çehreli MC, Iplikçioglu H. In vitro strain gauge analysis of axial and off-axial loading on implant supported fixed partial dentures. Implant Dent. 2002;11:286-92.

7- Frost MH. Wolff's Law and bone's structural adaptations to mechanical usage: an overview for clinicians. Angle Orthod. 1994;64:175-88.

8- Heckmann SM, Karl M, Wichmann MG, Winter W, Graef F, Taylor TD. Cement fixation and screw retention: parameters of passive fit. An in vitro study of three-unit implant-supported fixed partial dentures. Clin Oral Implants Res. 2004;15:466-73.

9- Heckmann SM, Karl M, Wichmann MG, Winter W, Graef F, Taylor TD. Loading of bone surrounding implants through three-unit fixed partial denture fixation: a finite-element analysis based on in vitro and in vivo strain measurements. Clin Oral Implants Res. 2006; 17:345-50.

10- Isidor F. Histological evaluation of peri-implant bone at implants subjected to occlusal overload or plaque accumulation. Clin Oral Implants Res. 1997;8:1-9.

11- Isidor F. Influence of forces on peri-implant bone. Clin Oral Implants Res. 2006;17(sp. Issue 2):8-18.

12- Isidor F. Loss of osseointegration caused by occlusal load of oral implants. A clinical and radiographic study in monkeys. Clin Oral Implants Res. 1996;7:143-52.

13- Kan JY, Rungcharassaeng K, Bohsali K, Goodacre CJ, Lang BR. Clinical methods for evaluating implant framework fit. J Prosthet Dent. 1999;81:7-13.

14- Kano SC, Bonfate G, Hussne R, Siqueira AF. Use of base metal casting alloys for implant framework: marginal accuracy analysis. J Appl Oral Sci. 2004;12:337-43.

15- Karl M, Rösch S, Graef F, Taylor TD, Heckmann SM. Strain situation after fixation of three-unit ceramic veneered implant superstructures. Implant Dent. 2005;14:157-65.
16- Karl M, Taylor TD, Wichmann MG, Heckmann SM. In vivo stress behavior in cementeded and screw-retained five-unit implant FPDs. J Prosthodont. 2006;15:20-4.

17- Karl M, Wichmann MG, Winter W, Graef F, Taylor TD, Heckmann SM. Influence of fixation mode and superstructure span upon strain development of implant fixed partial dentures. J Prosthodont. 2008;17:3-8.

18- Kim Y, Oh TJ, Misch CE, Wang HL. Oclusal considerations in implant therapy: clinical guidelines with biomechanical rationale. Clin Oral Implants Res. 2005;16:26-35.

19- Maeda $Y$, Satoh T, Sogo M. In vitro differences of stress concentrations for internal and external hex implant-abutment connections: a short communication. J Oral Rehabil. 2006;33:758.

20- May KB, Edge MJ, Russell MM, Razzoog ME, Lang BR. The precision of fit at the implant prosthodontic interface. J Prosthet Dent. 1997; 77:497-502.

21- Mericske-Stern R, Assal P, Merickse E, Bürgin W. Occlusal force and oral tactile sensibility measured in partially edentulous patients with ITI implants. Int J Oral Maxillofac Implants. 1995; 10:345-53. 22- Nishioka RS, Vasconcellos LGO, Melo Nishioka LN. External hexagon and internal hexagon in straight and offset implant placement: strain gauge analysis. Implant Dent. 2009;18:512-20. 23- Rangert $B$, Krogh $\mathrm{PHJ}$, Langer $B$, Van Roekel N. Bending overload and implant fracture: a retrospective clinical analysis. Int J Oral Maxillofac Implants. 1995;10:326-34.

24- Rangert BR, Sullivan RM, Jemt TM. Load factor control for implants in the posterior partially edentulous segment. Int J Oral Maxillofac Implants. 1997;12:360-70.

25- Sahin S, Çehreli MC, Yalçin E. The influence of functional forces on the biomechanics of implant-supported prostheses - a review. J Dent. 2002;30:271-82.

26- Seong WJ, Korioth TWP, Hodges JS. Experimentally induced abutment strains in three types of single-molar implant restorations. J Prosthet Dent. 2000;84:318-26.

27- Stegaroiu R, Sato T, Kusakari $H$, Miyakawa O. Influence of restoration type on stress distribuition in bone around implants: a three-dimensional finite element analysis. Int J Oral Maxillofac Implants. 1998; 13:82-90

28- Tada S, Stegaroiu R, Kitamura E, Miyakawa O, Kusakari H. Influence of implant design and bone quality on stress/strain distribuition in bone around implants: a 3-dimensional finite element analysis. Int J Oral Maxillofac Implants. 2003;18:357-68. 29- Ueda C, Markarian RA, Sendyk CL, Laganá DC. Photoelastic analysis of stress distribution on parallel and angled implants after installation of fixed prostheses. Braz Oral Res. 2004;18:45-52. 30- Wiskott HWA, Belser UC. Lack of integration of smooth titanium surfaces: a working hypothesis based on strains generated in the surrounding bone. Clin Oral Implants Res. 1999;10:429-44. 